Article

\title{
A Variable Control Chart under the Truncated Life Test for a Weibull Distribution
}

\author{
Nasrullah Khan ${ }^{1}$ (D), Muhammad Aslam ${ }^{2, *}$ (D), Muhammad Zahir Khan ${ }^{3}$ and Chi-Hyuck Jun ${ }^{4}$ \\ 1 Department of Statistics and Computer Science, University of Veterinary and Animal Sciences (UVAS), \\ Lahore 54000, Pakistan; nas_shan1@hotmail.com \\ 2 Department of Statistics, Faculty of Science, King Abdulaziz University, Jeddah 21551, Saudi Arabia \\ 3 Department of Mathematics and Statistics, Riphah International University, Islamabad 44000, Pakistan; \\ zerishkh@gmail.com \\ 4 Department of Industrial and Management Engineering, Pohang University of Science and \\ Technology (POSTECH), Pohang 37673, Korea; chjun@postech.ac.kr \\ * Correspondence: aslam_ravian@hotmail.com or magmuhammad@kau.edu.sa; Tel.: +966-59-332-9841
}

Received: 9 May 2018; Accepted: 7 June 2018; Published: 10 June 2018

check for updates

\begin{abstract}
In this manuscript, a variable control chart under the time truncated life test for the Weibull distribution is presented. The procedure of the proposed control chart is given and its run length properties are derived for the shifted process. The control limit is determined by considering the target in-control average run length $(A R L)$. The tables for $A R L s$ are presented for industrial use according to various shift parameters and shape parameters in the Weibull distribution. A simulation study is given for demonstrating the performance of the proposed control chart.
\end{abstract}

Keywords: average run length; variable chart; weibull distribution

\section{Introduction}

A control chart is considered a powerful tool for maintaining the high quality of products in industry. This tool is used to monitor the industrial process from raw material to final product. The process can shift from the target value due to several extraneous factors. The control chart should provide a quick indication about a shift in a manufacturing process, if there is any. This quick indication helps the industrial engineer to look at the problem and bring it back into control state.

Two types of control charts are widely used in the industry for monitoring the manufacturing process. Attribute control charts are used when the data is coming from the counting process and variable control charts are used when the data is obtained from the measurement process. The attribute control charts are easy to apply but the variable control charts are more informative than attribute charts. Usually, variables control charts are developed under the assumption that the characteristic follows the normal distribution.

In practice, a control chart designed for normal distribution may not be effective for monitoring the manufacturing process when the characteristic of interest does not follow the normal distribution. The use of this type of control chart may lead to a wrong decision about the status of the manufacturing state. Derya and Canan [1] mentioned that "the distributions of measurements in chemical processes, semiconductor processes, cutting tool wear processes and observations on lifetimes in accelerated life test samples are often skewed". Several authors focused on this issue and designed control charts for non-normal data. Al-Oraini and Rahim [2] designed a control chart for a gamma distribution. Amin et al. [3] designed a non-parametric chart using a sign statistic. Chang and Bai [4] worked for a control chart for a positive skewed population, Chen and Yeh [5] worked for an economical statistical design of a control chart for a gamma distribution. McCracken and Chakraborti [6] presented 
a control chart for monitoring mean and variance for a normal distribution. Yen et al. [7] designed a Synthetic-type contro for time between events. Riaz et al. [8] proposed a median control chart and Abujiya et al. [9] worked for the cumulative sum control chart (CUSUM) control chart. Gonzalez and Viles [10] designed a R chart using gamma distribution, Lio and Park [11] designed a control chart for inverse Gaussian percentiles. Huang and Pascual [12] designed a control chart for Weibull percentiles using the order statistic. Derya and Canan [1] designed the control charts for the Weibull distribution, gamma distribution, and log-normal distribution and [13] proposed a control chart for the Burr type $X$ distribution. Aslam et al. [14] deigned control chart for the exponential distribution using exponentially weighted moving average (EWMA) statistic.

For the reliability evaluation of a product, the time truncated life test is often adopted in industries for saving the experiment time. Therefore, the designing of a control chart under the time truncated test is important when monitoring the process in terms of reliability. Aslam et al. [15] proposed an attribute control chart under the time truncated life test by assuming that the failure time of a product follows the Weibull distribution. Aslam et al. [16] designed a time truncated attribute control chart using the Pareto distribution. Aslam et al. [17] deigned a time truncated control chart for the Birnbaum-Saunders distribution under repetitive sampling. More details about such control charts can be read in Aslam et al. [18], Arif et al. [19], Khan et al. [20], and Shafqat et al. [21].

In summary, control charts under the time truncated life test for various situations or distributions are available for the attribute quality of interest. However, these control charts cannot be applied for the monitoring of a measurable quality of interest. From exploring the literature and from the best of our knowledge, there is no work on the design of a variable control chart under the time truncated life test. In this paper, we will propose a variable control chart for a Weibull distribution using failure data from a time truncated life test. A real example is given for illustration purposes and a simulation study is added to demonstrate the performance of the proposed control chart.

\section{Proposed Chart and Its Average Run Length (ARLs)}

The assumptions of the proposed control chart are stated as follows:

1. It is assumed that the quality characteristic of interest follows a Weibull distribution.

2. The shape parameter $\beta$ of the Weibull distribution is assumed to be known.

3. When the process is shifted, the scale parameter is changed to $\lambda_{1}=c \lambda_{0}$, where $c$ is a shift constant and $\lambda_{0}$ is the scale parameter for the in-control process. The shape parameter remains unchanged when the process is shifted.

4. Failure times are measured during the time truncated life test.

Let the variable of interest follow the Weibull distribution with the cumulative distribution function (cdf) of:

$$
F(t ; \lambda, \beta)=1-\exp \left(-(t / \lambda)^{\beta}\right), t \geq 0
$$

where $\beta$ is the shape parameter and $\lambda$ is the scale parameter. The average life time, $\mu$, of the variable is given by:

$$
\mu=(\lambda / \beta)(\Gamma(1 / \beta))
$$

where $\Gamma($.$) is a gamma function.$

The proposed control chart is operated as follows:

Step 1 Take a sample of size $n$ at each subgroup from the production process. Put them on test until the specified time $t_{0}$.

Step 2 Obtain the time to failure of item $i$ (denoted by $X_{i}$ ). Set $X_{i}=t_{0}$ if item $i$ does not fail by time $t_{0}$. Calculate statistics $Y_{i}=X_{i}^{\beta}$.

Step 3 Obtain $\bar{Y}=\frac{1}{n} \sum_{i=1}^{n} Y_{i}, \bar{Y}$ is average of $Y_{i}$. Declare the process as in-control if $\bar{Y} \geq L_{3}$ or as out-of-control if $\bar{Y}<L_{3}$, where $L_{3}$ represents the control limit. 


\subsection{Distribution of Control Statistics and In-Control Average Run Length (ARL)}

To derive the necessary measures of average run length $(A R L)$, it would be convenient to select the specified time $t_{0}=a \mu_{0}$, as a fraction of the mean for the in control process, where $a$ is a constant and $\mu_{0}$ is the target mean.

As the transformed variable $Y=X^{\beta}$ is modeled to an exponential distribution with mean $\lambda^{\beta}$, the sum of $Y^{\prime}$ s (or $\bar{Y}$ ) follows a gamma distribution. But, the distribution of $\bar{Y}$ approximately follows a normal distribution according to the central limit theorem, as long as the sample size is sufficient. Then, the expected value of $\bar{Y}$ can be obtained by:

$$
E[\bar{Y}]=E\left[\frac{1}{n} \sum_{i=1}^{n} Y_{i}\right]=\frac{1}{n} \sum_{i=1}^{n} E\left[Y_{i}\right]=E\left[Y_{i}\right]
$$

Here, $E\left[Y_{i}\right]$ is obtained by:

$$
E\left[Y_{i}\right]=E\left[Y_{i} \mid Y_{i} \leq t_{0}^{\beta}\right] P\left\{Y_{i} \leq t_{0}^{\beta}\right\}+E\left[Y_{i} \mid Y_{i}>t_{0}^{\beta}\right] P\left\{Y_{i}>t_{0}^{\beta}\right\}
$$

Equation (4) reduces to:

$$
E\left[Y_{i}\right]=\int_{0}^{t_{0}^{\beta}} \frac{y}{\lambda_{0}^{\beta}} e^{-\frac{y}{\lambda_{0}^{\beta}}} d y+t_{0}^{\beta} \int_{t_{0}^{\beta}}^{\infty} \frac{1}{\lambda^{\beta}} e^{-\frac{y}{\lambda_{0}^{\beta}}} d y=\lambda_{0}^{\beta}\left(1-e^{-\left(\frac{t_{0}}{\lambda_{0}}\right)^{\beta}}\right)=E[\bar{Y}]
$$

The variance of $\bar{Y}$ is given as follows:

$$
\operatorname{ar}[\bar{Y}]=\frac{1}{n} \operatorname{Var}[Y]=\left(E\left[Y^{2}\right]-(E[Y])^{2}\right) / n
$$

The simplified form of $\operatorname{Var}[\bar{Y}]$ can be rewritten as:

$$
\operatorname{Var}[\bar{Y}]=\frac{1}{n}\left[\lambda_{0}^{2 \beta}\left(1-e^{-2\left(\frac{t_{0}}{\lambda_{0}}\right)^{\beta}}\right)-2\left(\lambda_{0} t_{0}\right)^{\beta} e^{-\left(\frac{t_{0}}{\lambda_{0}}\right)^{\beta}}\right]
$$

Let $P_{i n, 0}$ be the probability of being declared as in control when the process is actually in control at $\lambda_{0}$. Then, it is given as follows:

$$
P_{i n, 0}=P\left(\bar{Y} \geq L_{3} \mid \lambda=\lambda_{0}\right)
$$

Finally, $P_{i n, 0}$ can be written as follows:

$$
P_{i n, 0}=1-\Phi\left(\frac{L_{3}-\left(\frac{\beta \mu_{0}}{\Gamma\left(\frac{1}{\beta}\right)}\right)^{\beta}\left(1-e^{-\left(\frac{a}{\beta} \Gamma\left(\frac{1}{\beta}\right)\right)^{\beta}}\right)}{\sqrt{\frac{1}{n}\left[\left(\frac{\beta \mu_{0}}{\Gamma\left(\frac{1}{\beta}\right)}\right)^{2 \beta}\left(1-e^{-2\left(\frac{a}{\beta} \Gamma\left(\frac{1}{\beta}\right)\right)^{\beta}}\right)-2\left(\frac{a \beta \mu_{0}^{2}}{\Gamma\left(\frac{1}{\beta}\right)}\right)^{\beta} e^{-\left(\frac{a}{\beta} \Gamma\left(\frac{1}{\beta}\right)\right)^{\beta}}\right]}}\right)
$$

The efficiency of the proposed chart will be measured through the $A R L$, which shows when the process will be out-of-control. Let $A R L_{0}$ be the $A R L$ for in control process. Then, it is given as follows:

$$
A R L_{0}=\frac{1}{1-P_{i n, 0}}
$$




\subsection{Out of Control ARL}

Let us assume that the process has shifted due to some factors to a new scale parameter $\lambda_{1}=c \lambda_{0}$, where $c$ is the shift constant. Now, we derive the measures for the shifted process. Let $P_{i n, 1}$ be the probability of declaring the state of being in control when the process has shifted to $\lambda_{1}$, which is given as follows:

$$
P_{\text {in, } 1}=P\left(\bar{Y} \geq L_{3} \mid \lambda=\lambda_{1}\right)
$$

The distribution of $\bar{Y}$ at $\lambda_{1}$ approximately follows normal with the mean and the variance given below:

$$
\begin{gathered}
E\left[\bar{Y} \mid \lambda_{1}\right]=\lambda_{1}^{\beta}\left(1-e^{-\left(\frac{t_{0}}{\lambda_{1}}\right)^{\beta}}\right) \\
\operatorname{Var}[\bar{Y}]=\frac{1}{n}\left[\lambda_{1}^{2 \beta}\left(1-e^{-2\left(\frac{t_{0}}{\lambda_{1}}\right)^{\beta}}\right)-2\left(\lambda_{1} t_{0}\right)^{\beta} e^{-\left(\frac{t_{0}}{\lambda_{1}}\right)^{\beta}}\right]
\end{gathered}
$$

Therefore, the in-control probability for the shifted process, say $P_{i n, 1}$ in Equation (11), is obtained by:

$$
P_{i n, 1}=1-\Phi\left(\frac{L_{3}-\left(\frac{c \beta \mu_{0}}{\Gamma\left(\frac{1}{\beta}\right)}\right)^{\beta}\left(1-e^{-\left(\frac{a}{c \beta} \Gamma\left(\frac{1}{\beta}\right)\right)^{\beta}}\right)}{\sqrt{\frac{1}{n}\left[\left(\frac{c \beta \mu_{0}}{\Gamma\left(\frac{1}{\beta}\right)}\right)^{2 \beta}\left(1-e^{-2\left(\frac{a}{c \beta} \Gamma\left(\frac{1}{\beta}\right)\right)^{\beta}}\right)-2\left(\frac{a c \beta \mu_{0}^{2}}{\Gamma\left(\frac{1}{\beta}\right)}\right)^{\beta} e^{-\left(\frac{a}{c \beta} \Gamma\left(\frac{1}{\beta}\right)\right)^{\beta}}\right]}}\right)
$$

Hence, the out-of-control $A R L$, say $A R L_{1}$ for the shifted process is given as follows:

$$
A R L_{1}=\frac{1}{1-P_{i n, 1}}
$$

The values of $A R L_{1}$ for the various values of the shape parameters, $\mu_{0}, c$ and, $r_{0}$, are presented in Tables 1-8. Let $r_{0}$ be the specified in-control $A R L$. The control limit $L_{3}$ is determined by using the following algorithm:

1. Prefix the value of $r_{0}$.

2. The value $L_{3}$ is obtained such that $A R L_{0} \geq r_{0}$.

Table 1. The values of $A R L s$ when $r_{0}=370, \beta=0.5$, and $\mu_{0}=50$.

\begin{tabular}{ccccccccc}
\hline \multicolumn{7}{c}{$a$} \\
\hline & 0.1 & 0.2 & 0.4 & 0.5 & 0.7 & 0.9 & 1 & 1.5 \\
$L$ & 1.45 & 1.80 & 2.15 & 2.25 & 2.39 & 2.47 & 2.51 & 2.60 \\
\hline$c$ & \multicolumn{7}{c}{$A \boldsymbol{R L}_{\mathbf{1}}$} \\
\hline 1 & 371.89 & 370.16 & 370.03 & 370.20 & 370.32 & 370.00 & 370.15 & 370.37 \\
0.9 & 206.44 & 198.53 & 193.29 & 192.28 & 191.36 & 191.09 & 191.28 & 192.92 \\
0.8 & 111.78 & 103.82 & 98.36 & 97.24 & 96.19 & 95.91 & 96.03 & 97.43 \\
0.7 & 58.89 & 52.83 & 48.67 & 47.80 & 46.94 & 46.69 & 46.72 & 47.57 \\
0.6 & 30.11 & 26.12 & 23.40 & 22.82 & 22.23 & 22.02 & 22.01 & 22.41 \\
0.5 & 14.92 & 12.56 & 10.96 & 10.61 & 10.24 & 10.09 & 10.07 & 10.20 \\
0.4 & 7.18 & 5.90 & 5.05 & 4.86 & 4.65 & 4.56 & 4.54 & 4.55 \\
0.3 & 3.40 & 2.78 & 2.38 & 2.28 & 2.18 & 2.12 & 2.11 & 2.09 \\
0.2 & 1.67 & 1.43 & 1.27 & 1.24 & 1.20 & 1.18 & 1.17 & 1.16 \\
0.1 & 1.04 & 1.01 & 1.00 & 1.00 & 1.00 & 1.00 & 1.00 & 1.00 \\
\hline
\end{tabular}


Table 2. The values of $A R L s$ when $r_{0}=370, \beta=0.5$, and $\mu_{0}=100$.

\begin{tabular}{ccccccccc}
\hline \multicolumn{7}{c}{$a$} \\
\hline & 0.1 & 0.2 & 0.4 & 0.5 & 0.7 & 0.9 & 1 & 1.5 \\
$L$ & 2.05 & 2.55 & 3.04 & 3.18 & 3.38 & 3.50 & 3.54 & 3.68 \\
\hline$c$ & \multicolumn{7}{c}{$A L_{1} \mathbf{1}$} \\
\hline 1 & 370.08 & 370.09 & 370.40 & 370.05 & 370.20 & 370.03 & 370.04 & 370.04 \\
0.9 & 205.51 & 198.49 & 193.48 & 192.21 & 191.31 & 191.10 & 191.23 & 192.75 \\
0.8 & 111.32 & 103.81 & 98.45 & 97.21 & 96.16 & 95.92 & 96.00 & 97.35 \\
0.7 & 58.67 & 52.82 & 48.71 & 47.78 & 46.93 & 46.69 & 46.71 & 47.53 \\
0.6 & 30.02 & 26.12 & 23.42 & 22.81 & 22.22 & 22.02 & 22.01 & 22.39 \\
0.5 & 14.88 & 12.55 & 10.97 & 10.61 & 10.24 & 10.09 & 10.07 & 10.20 \\
0.4 & 7.16 & 5.90 & 5.05 & 4.86 & 4.65 & 4.56 & 4.53 & 4.55 \\
0.3 & 3.39 & 2.78 & 2.38 & 2.28 & 2.18 & 2.12 & 2.11 & 2.09 \\
0.2 & 1.67 & 1.43 & 1.27 & 1.24 & 1.20 & 1.18 & 1.17 & 1.16 \\
0.1 & 1.04 & 1.01 & 1.00 & 1.00 & 1.00 & 1.00 & 1.00 & 1.00 \\
\hline
\end{tabular}

Table 3. The values of ARLs when $r_{0}=370, \beta=1$, and $\mu_{0}=50$.

\begin{tabular}{|c|c|c|c|c|c|c|c|c|}
\hline & \multicolumn{8}{|c|}{$a$} \\
\hline & 0.1 & 0.2 & 0.4 & 0.5 & 0.7 & 0.9 & 1 & 1.5 \\
\hline 13 & 4.32 & 7.88 & 13.44 & 15.61 & 19.05 & 21.53 & 22.49 & 25.39 \\
\hline$c$ & \multicolumn{8}{|c|}{$A R L_{1}$} \\
\hline 1 & 370.49 & 370.04 & 370.05 & 370.04 & 370.02 & 370.02 & 370.00 & 370.03 \\
\hline 0.9 & 160.24 & 140.34 & 121.26 & 115.86 & 109.00 & 105.29 & 104.19 & 103.22 \\
\hline 0.8 & 69.80 & 54.24 & 41.14 & 37.75 & 33.62 & 31.43 & 30.77 & 29.92 \\
\hline 0.7 & 30.74 & 21.55 & 14.70 & 13.06 & 11.14 & 10.13 & 9.81 & 9.30 \\
\hline 0.6 & 13.78 & 8.94 & 5.69 & 4.97 & 4.14 & 3.71 & 3.57 & 3.30 \\
\hline 0.5 & 6.36 & 3.97 & 2.51 & 2.21 & 1.86 & 1.69 & 1.63 & 1.50 \\
\hline 0.4 & 3.10 & 1.98 & 1.38 & 1.26 & 1.14 & 1.09 & 1.07 & 1.04 \\
\hline 0.3 & 1.67 & 1.22 & 1.03 & 1.02 & 1.00 & 1.00 & 1.00 & 1.00 \\
\hline 0.2 & 1.11 & 1.01 & 1.00 & 1.00 & 1.00 & 1.00 & 1.00 & 1.00 \\
\hline 0.1 & 1.00 & 1.00 & 1.00 & 1.00 & 1.00 & 1.00 & 1.00 & 1.00 \\
\hline
\end{tabular}

Table 4. The values of ARLs when $r_{0}=370, \beta=1$, and $\mu_{0}=100$.

\begin{tabular}{ccccccccc}
\hline \multicolumn{7}{c}{$a$} \\
\hline & 0.1 & 0.2 & 0.4 & 0.5 & 0.7 & 0.9 & 1 & 1.5 \\
13 & 8.63 & 15.75 & 26.87 & 31.22 & 38.09 & 43.05 & 44.98 & 50.77 \\
\hline$c$ & \multicolumn{7}{c}{$A R L_{1}$} \\
\hline 1 & 370.11 & 370.15 & 370.00 & 370.00 & 370.02 & 370.01 & 370.01 & 370.01 \\
0.9 & 160.10 & 140.38 & 121.25 & 115.85 & 109.00 & 105.29 & 104.19 & 103.21 \\
0.8 & 69.75 & 54.25 & 41.14 & 37.75 & 33.62 & 31.43 & 30.77 & 29.92 \\
0.7 & 30.72 & 21.55 & 14.70 & 13.06 & 11.14 & 10.13 & 9.81 & 9.30 \\
0.6 & 13.77 & 8.94 & 5.69 & 4.97 & 4.14 & 3.71 & 3.57 & 3.30 \\
0.5 & 6.36 & 3.97 & 2.51 & 2.21 & 1.86 & 1.69 & 1.63 & 1.50 \\
0.4 & 3.10 & 1.98 & 1.37 & 1.26 & 1.14 & 1.09 & 1.07 & 1.04 \\
0.3 & 1.67 & 1.22 & 1.03 & 1.02 & 1.00 & 1.00 & 1.00 & 1.00 \\
0.2 & 1.11 & 1.01 & 1.00 & 1.00 & 1.00 & 1.00 & 1.00 & 1.00 \\
0.1 & 1.00 & 1.00 & 1.00 & 1.00 & 1.00 & 1.00 & 1.00 & 1.00 \\
\hline
\end{tabular}


Table 5. The values of $A R L s$ when $r_{0}=370, \beta=1.5$, and $\mu_{0}=50$.

\begin{tabular}{|c|c|c|c|c|c|c|c|c|}
\hline & \multicolumn{8}{|c|}{$a$} \\
\hline & 0.1 & 0.2 & 0.4 & 0.5 & 0.7 & 0.9 & 1 & 1.5 \\
\hline 13 & 10.50 & 27.97 & 69.43 & 90.44 & 129.08 & 160.79 & 173.68 & 211.26 \\
\hline$c$ & \multicolumn{8}{|c|}{$A R L_{1}$} \\
\hline 1 & 370.72 & 370.42 & 370.06 & 370.00 & 370.02 & 370.08 & 370.05 & 370.01 \\
\hline 0.9 & 141.52 & 116.13 & 88.08 & 79.62 & 68.53 & 62.25 & 60.30 & 58.10 \\
\hline 0.8 & 56.58 & 39.16 & 23.78 & 19.89 & 15.29 & 12.91 & 12.18 & 11.10 \\
\hline 0.7 & 23.78 & 14.36 & 7.50 & 6.00 & 4.36 & 3.56 & 3.32 & 2.88 \\
\hline 0.6 & 10.57 & 5.83 & 2.89 & 2.33 & 1.74 & 1.48 & 1.40 & 1.25 \\
\hline 0.5 & 5.01 & 2.70 & 1.47 & 1.27 & 1.09 & 1.03 & 1.02 & 1.00 \\
\hline 0.4 & 2.58 & 1.50 & 1.06 & 1.02 & 1.00 & 1.00 & 1.00 & 1.00 \\
\hline 0.3 & 1.50 & 1.07 & 1.00 & 1.00 & 1.00 & 1.00 & 1.00 & 1.00 \\
\hline 0.2 & 1.07 & 1.00 & 1.00 & 1.00 & 1.00 & 1.00 & 1.00 & 1.00 \\
\hline 0.1 & 1.00 & 1.00 & 1.00 & 1.00 & 1.00 & 1.00 & 1.00 & 1.00 \\
\hline 0 & 1.00 & 1.00 & 1.00 & 1.00 & 1.00 & 1.00 & 1.00 & 1.00 \\
\hline
\end{tabular}

Table 6. The values of $A R L s$ when $r_{0}=370, \beta=1.5$, and $\mu_{0}=100$.

\begin{tabular}{ccccccccc}
\hline \multicolumn{7}{c}{$a$} \\
\hline & 0.1 & 0.2 & 0.4 & 0.5 & 0.7 & 0.9 & 1 & 1.5 \\
13 & 29.69 & 79.11 & 196.38 & 255.81 & 365.10 & 454.78 & 491.26 & 597.52 \\
\hline $\boldsymbol{c}$ & \multicolumn{7}{c}{$A R L_{1}$} \\
\hline 1 & 370.53 & 370.08 & 370.17 & 370.00 & 370.00 & 370.00 & 370.01 & 370.00 \\
0.9 & 141.46 & 116.05 & 88.10 & 79.61 & 68.52 & 62.24 & 60.30 & 58.10 \\
0.8 & 56.56 & 39.14 & 23.78 & 19.89 & 15.29 & 12.90 & 12.18 & 11.10 \\
0.7 & 23.78 & 14.35 & 7.50 & 6.00 & 4.36 & 3.56 & 3.32 & 2.88 \\
0.6 & 10.57 & 5.83 & 2.89 & 2.33 & 1.74 & 1.48 & 1.40 & 1.25 \\
0.5 & 5.01 & 2.70 & 1.47 & 1.27 & 1.09 & 1.03 & 1.02 & 1.00 \\
0.4 & 2.58 & 1.50 & 1.06 & 1.02 & 1.00 & 1.00 & 1.00 & 1.00 \\
0.3 & 1.50 & 1.07 & 1.00 & 1.00 & 1.00 & 1.00 & 1.00 & 1.00 \\
0.2 & 1.07 & 1.00 & 1.00 & 1.00 & 1.00 & 1.00 & 1.00 & 1.00 \\
0.1 & 1.00 & 1.00 & 1.00 & 1.00 & 1.00 & 1.00 & 1.00 & 1.00 \\
\hline
\end{tabular}

Table 7. The values of $A R L s$ when $r_{0}=370, \beta=2$, and $\mu_{0}=50$.

\begin{tabular}{|c|c|c|c|c|c|c|c|c|}
\hline & \multicolumn{8}{|c|}{$a$} \\
\hline & 0.1 & 0.2 & 0.4 & 0.5 & 0.7 & 0.9 & 1 & 1.5 \\
\hline 13 & 24.25 & 93.32 & 336.83 & 493.78 & 832.31 & 1150.16 & 1286.31 & 1659.85 \\
\hline$c$ & \multicolumn{8}{|c|}{$A R L_{1}$} \\
\hline 1 & 389.83 & 373.30 & 370.04 & 370.08 & 370.04 & 370.02 & 370.03 & 370.01 \\
\hline 0.9 & 133.38 & 103.35 & 70.29 & 60.00 & 46.42 & 38.84 & 36.53 & 34.42 \\
\hline 0.8 & 50.14 & 32.53 & 16.66 & 12.77 & 8.41 & 6.33 & 5.73 & 4.93 \\
\hline 0.7 & 20.67 & 11.69 & 5.06 & 3.73 & 2.39 & 1.82 & 1.67 & 1.41 \\
\hline 0.6 & 9.34 & 4.83 & 2.06 & 1.60 & 1.19 & 1.06 & 1.03 & 1.00 \\
\hline 0.5 & 4.62 & 2.34 & 1.20 & 1.07 & 1.00 & 1.00 & 1.00 & 1.00 \\
\hline 0.4 & 2.50 & 1.38 & 1.01 & 1.00 & 1.00 & 1.00 & 1.00 & 1.00 \\
\hline 0.3 & 1.51 & 1.05 & 1.00 & 1.00 & 1.00 & 1.00 & 1.00 & 1.00 \\
\hline 0.2 & 1.08 & 1.00 & 1.00 & 1.00 & 1.00 & 1.00 & 1.00 & 1.00 \\
\hline 0.1 & 1.00 & 1.00 & 1.00 & 1.00 & 1.00 & 1.00 & 1.00 & 1.00 \\
\hline
\end{tabular}


Table 8. The values of $A R L s$ when $r_{0}=370, \beta=2$, and $\mu_{0}=100$.

\begin{tabular}{|c|c|c|c|c|c|c|c|c|}
\hline & \multicolumn{8}{|c|}{$r_{0}=370 ; \beta=1.5 ; u_{0}=100$} \\
\hline & \multicolumn{8}{|c|}{$a$} \\
\hline & 0.1 & 0.2 & 0.4 & 0.5 & 0.7 & 0.9 & 1 & 1.5 \\
\hline 13 & 97.02 & 373.31 & 1347.30 & 1975.12 & 3329.23 & 4600.66 & 5145.24 & 6639.42 \\
\hline$c$ & \multicolumn{8}{|c|}{$A R L_{1}$} \\
\hline 1 & 373.80 & 370.47 & 370.01 & 370.06 & 370.01 & 370.01 & 370.01 & 370.00 \\
\hline 0.9 & 128.96 & 102.73 & 70.29 & 59.99 & 46.42 & 38.84 & 36.53 & 34.42 \\
\hline 0.8 & 48.83 & 32.38 & 16.66 & 12.77 & 8.41 & 6.33 & 5.73 & 4.93 \\
\hline 0.7 & 20.27 & 11.65 & 5.06 & 3.73 & 2.39 & 1.82 & 1.67 & 1.41 \\
\hline 0.6 & 9.21 & 4.82 & 2.06 & 1.60 & 1.19 & 1.06 & 1.03 & 1.00 \\
\hline 0.5 & 4.57 & 2.34 & 1.20 & 1.07 & 1.00 & 1.00 & 1.00 & 1.00 \\
\hline 0.4 & 2.49 & 1.38 & 1.01 & 1.00 & 1.00 & 1.00 & 1.00 & 1.00 \\
\hline 0.3 & 1.51 & 1.05 & 1.00 & 1.00 & 1.00 & 1.00 & 1.00 & 1.00 \\
\hline 0.2 & 1.08 & 1.00 & 1.00 & 1.00 & 1.00 & 1.00 & 1.00 & 1.00 \\
\hline 0.1 & 1.00 & 1.00 & 1.00 & 1.00 & 1.00 & 1.00 & 1.00 & 1.00 \\
\hline
\end{tabular}

From Tables 1-8 and Figure 1, we note the following trends in $A R L_{1}$.

1. As $a$ increases, we note $A R L_{1}$ to decrease for the same shift in process. This seems reasonable because the number of failures observed increases as $a$ increases.

2. For a fixed $a$, as $c$ decreases, $A R L_{1}$ also decreases because the true mean time to a failure decreases.

3. For other fixed parameters, as $\mu_{0}$ increases from 50 to 100, the behavior of $A R L_{1}$ remains quite similarly, which is a desirable feature.

4. For other fixed parameters, as $\beta$ increases from 0.5 to $2, A R L_{1}$ decreases.
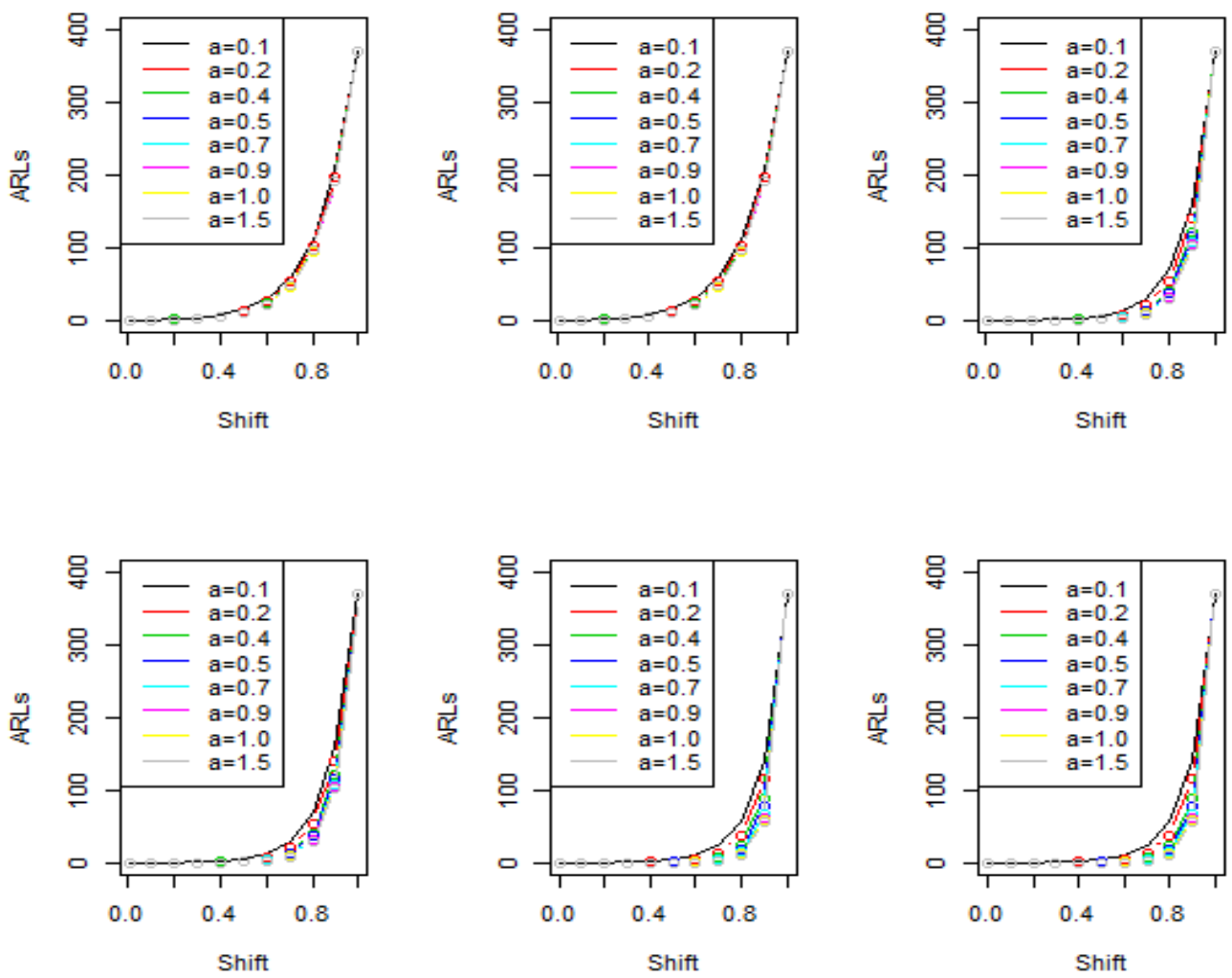

Figure 1. The average run length (ARLs) curves. 


\section{Simulation Study}

In this section, we discuss the performance of the proposed control chart using simulated data. The data is generated from the Weibull distribution with the shape parameters $\beta=1.5$ and $\mu_{0}=50$. The first 20 observations are generated from an in-control process and the next 20 observations are generated from a shifted process with $c=0.8$.

We applied this data to the proposed control chart having $a=1$ and $r_{0}=370$. The control limit $L_{3}$ is obtained by 173.68. The values of $Y_{i}=X_{i}^{1.5}$ are calculated and plotted on the control chart. From Figure 2, we note that the proposed chart detects the shift in the process at the 31st sample.

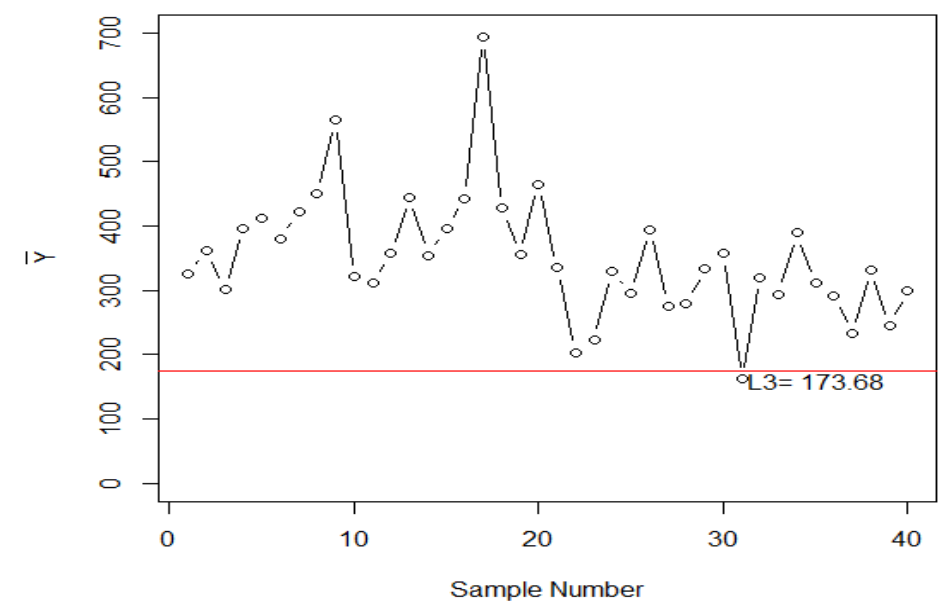

Figure 2. The proposed chart using simulated data.

\section{Real Example}

In this section, we will discuss the application of the proposed control chart using the breaking stress data of carbon fibers from an industry. Carbon fiber has good tensile strength, which is measured in force per unit area (GPa). For more details, see Yu et al. [22]. The carbon fibers data given in GPa is modeled by the Weibull distribution when $a=1$. For this study, let $n=30$ and $r_{0}=370$. The values of statistic $\bar{Y}$ for this data are shown below:

$404,377,420,698,402,421,352,303,544,413,365,359,383,330,451,402,355,368,342,383,444,368$, $364,433,443,508,447,528,512,559,481,325,303,410,628,373,571,414,364,328$.

By plotting $\bar{Y}$ on a control chart, Figure 3 shows that the process is in control but some points are close to the lower control limit.

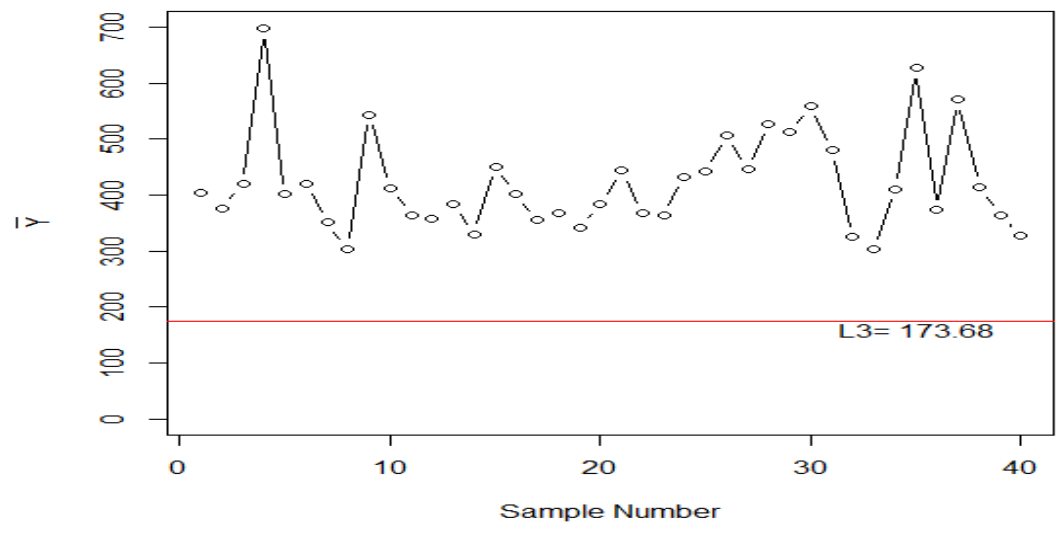

Figure 3. Proposed chart for the carbon fibers data. 


\section{Conclusions}

In this paper, a new variable chart under the truncated life test is designed for the Weibull distribution. The average run length is derived to measure the efficiency of the proposed chart. Extensive tables are given for industrial use. The application of the proposed chart is given with the help of simulation data. The proposed chart is sensitive in detecting the shift in the process. The proposed control chart can be used in a real industry where the lifetime of the product follows the Weibull distribution. The proposed chart using unknown shape parameters can be a fruitful future research.

Author Contributions: Conceptualization, N.K., M.A., M.Z.K. and C.H.J.; Methodology, N.K., M.A., M.Z.K. and C.H.J.; Software, N.K., M.A., M.Z.K. and C.H.J.; Validation, N.K., M.A., M.Z.K. and C.H.J; Formal Analysis, N.K., M.A., M.Z.K. and C.H.J.; Writing-Original Draft Preparation, M.A., and C.H.J.; Writing-Review \& Editing, N.K., M.A., M.Z.K. and C.H.J.

Funding: This research received no external funding.

Acknowledgments: The authors are deeply thankful to the editor and the reviewers for their valuable suggestions to improve the quality of this manuscript. This article was funded by the Deanship of Scientific Research (DSR) at King Abdulaziz University, Jeddah. The author, Muhammad Aslam, therefore, acknowledge with thanks DSR technical and financial support.

Conflicts of Interest: The authors declare no conflict of interest.

\section{References}

1. Derya, K.; Canan, H. Control Charts for Skewed Distributions: Weibull, Gamma, and Lognormal. Metodoloski Zvezki 2012, 9, 95-106.

2. Al-Oraini, H.A.; Rahim, M. Economic statistical design of $X$ control charts for systems with Gamma $(\lambda, 2)$ in-control times. Comput. Ind. Eng. 2002, 43, 645-654. [CrossRef]

3. Amin, R.W.; Reynolds, M.R., Jr.; Saad, B. Nonparametric quality control charts based on the sign statistic. Commun. Stat.-Theor. Methods 1995, 24, 1597-1623. [CrossRef]

4. Chang, Y.S.; Bai, D.S. Control charts for positively-skewed populations with weighted standard deviations. Qual. Reliab. Eng. Int. 2001, 17, 397-406. [CrossRef]

5. Chen, F.; Yeh, C. Economic statistical design of non-uniform sampling scheme X bar control charts under non-normality and Gamma shock using genetic algorithm. Expert Syst. Appl. 2009, 36, 9488-9497. [CrossRef]

6. McCracken, A.; Chakraborti, S. Control charts for joint monitoring of mean and variance: An overview. Qual. Technol. Quant. Manag. 2013, 10, 17-35. [CrossRef]

7. Yen, F.Y.; Chong, K.M.B.; Ha, L.M. Synthetic-type control charts for time-between-events monitoring. PLoS ONE 2013, 8, e65440. [CrossRef] [PubMed]

8. Ahmad, S.; Riaz, M.; Abbasi, S.A.; Lin, Z. On efficient median control charting. J. Chin. Inst. Eng. 2014, 37, 358-375. [CrossRef]

9. Abujiya, M.R.; Riaz, M.; Lee, M.H. Enhanced Cumulative Sum Charts for Monitoring Process Dispersion. PLoS ONE 2015, 10, e0124520. [CrossRef] [PubMed]

10. Gonzalez, I.M.; Viles, E. Design of R control chart assuming a gamma distribution. Econ. Qual. Control 2001, 16, 199-204. [CrossRef]

11. Lio, Y.; Park, C. A bootstrap control chart for inverse Gaussian percentiles. J. Stat. Comput. Simul. 2010, 80, 287-299. [CrossRef]

12. Huang, X.; Pascual, F. ARL-unbiased control charts with alarm and warning lines for monitoring Weibull percentiles using the first-order statistic. J. Stat. Comput. Simul. 2011, 81, 1677-1696. [CrossRef]

13. Lio, Y.L.; Tsai, T.-R.; Aslam, M.; Jiang, N. Control charts for monitoring Burr type-X percentiles. Commun. Stat.-Simul. Comput. 2014, 43, 761-776. [CrossRef]

14. Aslam, M.; Azam, M.; Jun, C.-H. A new control chart for exponential distributed life using EWMA. Trans. Inst. Meas. Control 2015, 37, 205-210. [CrossRef]

15. Aslam, M.; Jun, C.-H. Attribute Control Charts for the Weibull Distribution under Truncated Life Tests. Qual. Eng. 2015, 27, 283-288. [CrossRef] 
16. Aslam, M.; Khan, N.; Jun, C.-H. A control chart for time truncated life tests using Pareto distribution of second kind. J. Stat. Comput. Simul. 2016, 86, 2113-2122. [CrossRef]

17. Aslam, M.; Arif, O.H.; Jun, C.-H. An Attribute Control Chart Based on the Birnbaum-Saunders Distribution Using Repetitive Sampling. In IEEE Access; IEEE: Washington, DC, USA, 2016.

18. Aslam, M.; Arif, O.H.; Jun, C.-H. An attribute control chart for a Weibull distribution under accelerated hybrid censoring. PLoS ONE 2017, 12, e0173406. [CrossRef] [PubMed]

19. Arif, O.-H.; Aslam, M.; Jun, C.-H. EWMA np Control Chart for the Weibull Distribution. J. Test. Eval. 2016, 45, 1022-1028. [CrossRef]

20. Khan, N.; Aslam, M.; Kim, K.-J.; Jun, C.-H. A mixed control chart adapted to the truncated life test based on the Weibull distribution. Oper. Res. Decis. 2017, 27, 43-55.

21. Shafqat, A.; Hussain, J.; Al-Nasser, A.D.; Aslam, M. Attribute control chart for some popular distributions. Commun. Stat.-Theor. Methods 2018, 47, 1978-1988. [CrossRef]

22. Yu, M.F.; Lourie, O.; Dyer, M.J.; Moloni, K.; Kelly, T.F.; Ruoff, R.S. Strength and breaking mechanism of multiwalled carbon nanotubes under tensile load. Science 2000, 287, 637-640. [CrossRef] [PubMed]

(C) 2018 by the authors. Licensee MDPI, Basel, Switzerland. This article is an open access article distributed under the terms and conditions of the Creative Commons Attribution (CC BY) license (http:/ / creativecommons.org/licenses/by/4.0/). 